\section{Estudo \\ Ecidebate}

em Testão

Plamejamento
Revista Estudo \& Debate, Lajeado, v. 24, n. 1, 2017. ISSN 1983-036X

DOI: http://dx.doi.org/10.22410/issn.1983-036X.v24i1a2017.1184

\title{
CONFLITOS HÍDRICOS E EDUCOMUNICAÇÃO SOCIOAMBIENTAL: CONTRIBUIÇÓES DAS METODOLOGIAS PARTICIPATIVAS ${ }^{1}$
}

\author{
Luzia Klunk², Jane Márcia Mazzarino $^{3}$
}

\begin{abstract}
Resumo: A confrontação de interesses sociais em decorrência dos diversos usos dos recursos naturais gera conflitos socioambientais. Os elementos que compóem os conflitos socioambientais são múltiplos, pois sofrem interferência de aspectos históricos, políticos, culturais, econômicos, etc. Por esse motivo, o seu tratamento efetivo, por vezes, depende da participação e do engajamento dos sujeitos envolvidos. Para tanto, a mediação e a educomunicação socioambiental podem ser mecanismos para alcançar processos de governança, baseado na integração e no compartilhamento de objetivos. Neste artigo é realizada uma revisão bibliográfica para refletir sobre a contribuição da educomunicação socioambiental na busca por compreender situaçôes de conflitos socioambientais e seu possível avanço em direçáo a processos de governança, a partir das múltiplas mediaçóes que o marcam.
\end{abstract}

Palavras-chave: Conflitos hídricos. Mediações. Educomunicação socioambiental. Metodologias participativas.

\section{MEDIATIONS AND WATER CONFLICTS: CONTRIBUTIONS OF PARTICIPATORY METHODOLOGIES}

\begin{abstract}
The confrontation of social interests due to the different uses of the natural resources generates socio-environmental conflicts. The elements that create the socio-environmental conflicts are multiple, as they suffer interference of various aspects as historical, political, cultural, economic, etc. For this reason, its effective treatment, sometimes, depends on the participation and commitment of the individuals involved. For this, the mediation and the socio-environmental educommunication may be the mechanisms to achieve governance processes based on the integration and sharing of goals. This paper presents a bibliographical revision in order
\end{abstract}

1 Esta pesquisa conta com apoio da Coordenação de Aperfeiçoamento de Pessoal de Nível Superior (CAPES) e do Conselho Nacional de Desenvolvimento Científico e Tecnológico (CNPq).

2 Doutoranda do PPG Ambiente e Desenvolvimento, Centro Universitário Univates, Lajeado-RS/BR. Bolsista PROSUP/CAPES. Membro do Grupo de Pesquisa Comunicação, Educação Ambiental e Intervenções CEAMI (CNPq). E-mail: luzia.klunk@univates.br

3 Doutora em Ciências da Comunicação, Unisinos. Docente Permanente do PPG Ambiente e Desenvolvimento, Centro Universitário Univates, Lajeado-RS/BR. Coordenadora do Grupo de Pesquisa Comunicação, Educação Ambiental e Intervençóes - CEAMI (CNPq). E-mail: janemazzarino@univates.br 
to think about the socio-environmental educommunication contributions in the search for comprehending situations of social-environmental conflicts, and its possible progress toward governance processes, from the multiple mediations that mark them.

Keywords: Water conflicts. Mediations. Socio-environmental educommunication. Participatory methodologies.

\section{INTRODUÇÁO}

Os diversos interesses de usos dos recursos naturais geram disputas ambientais. Esses conflitos abarcam diversos aspectos, como questóes históricas, culturais, sociais, econômicas, política etc. As interconexôes desses elementos conferem uma complexidade ao estudo sobre conflitos socioambientais. Com relação ao conflito hídrico, além da complexidade dos campos que o permeiam, deve-se considerar que a água é elemento vital e escasso. Por isso, o tratamento do conflito socioambiental hídrico, e suas possibilidades de gerar processos de governança, passa pela participação e diálogo, que podem ser estimulados por metodologias participativas, a partir da mediação e da educomunicação socioambiental.

Durante séculos o meio ambiente foi visto como fonte inesgotável de recursos. Porém, o surgimento de inúmeros problemas ambientais nas últimas décadas fez ressurgir velhos temas da sobrevivência humana, colocando o tema no centro do cenário econômico e político (LITTLE, 2001).

Little (2001, p. 115) refere que "em geral, os conflitos socioambientais mais difíceis tendem a acontecer onde há um choque entre diferentes sistemas produtivos". A Revoluçáo Industrial se fundamentou na ideologia do crescimento e representou a intensidade dos impactos ambientais. Porém, alguns grupos tradicionais mantêm sua sustentação por meio da exploração direta do ecossistema que os circunda. O choque entre os distintos sistemas de produção tem como consequência, muitas vezes, o conflito socioambiental (LITTLE, 2001).

O conflito socioambiental expressa um conflito de racionalidades: capitalista e ambiental, que se expressam na confrontação de interesses sociais arraigados em estruturas institucionais, processos de legitimação e formas de compreensão do mundo que enfrentam os diferentes agentes sociais. "A racionalidade ambiental que orienta a construçáo da sustentabilidade implica um encontro de racionalidades - de formas diferentes de pensar, de imaginar, de sentir, de significar e de dar valor às coisas do mundo" (LEFF, 2006, p. 249).

Historicamente, a contínua mudança caracterizava quase que estritamente os modos de produção e a economia. Porém, modernamente outros âmbitos se caracterizam também pela dinamicidade de relaçóes e pela "ausência de forma" (SIMMEL, 2013, p. 121). Esta dinamicidade também é um elemento que interfere nas relaçôes socioambientais contemporâneas.

Com relação aos recursos hídricos trazem um caráter conflituoso, pelo seu comercial e caráter vital, na medida em que há diferentes interesses de uso. A partir disso, questionase como o conflito socioambiental hídrico pode ser tratado por meio do diálogo e de uma perspectiva mais inclusiva e como as metodologias que estimulem a participação, utilizadas na mediação e na educomunicação socioambiental, contribuem na construção de processos de governança. 
O objetivo deste artigo é refletir sobre a contribuição da educomunicação socioambiental na busca por compreender situaçóes de conflitos socioambientais e seu possível avanço em direção a processos de governança, a partir das múltiplas mediaçóes que o marcam. São recorrentes os estudos isolados dos conceitos, havendo poucas análises das suas aproximaçóes, não tendo sido encontrados trabalhos similares sobre o tema.

\section{PROCEDIMENTO METODOLÓGICO}

Neste artigo é realizada uma revisão bibliográfica acerca dos conceitos de conflitos socioambientais, mais especificamente os hídricos, suas mediaçóes e a educomunicação socioambiental como um possível elemento gerador de processos de governança. Para tanto, foi necessário caracterizar e aprofundar os elementos que compóem esses conceitos, realizando-se cruzamentos e aproximaçóes.

Para esta caracterização bibliográfica utilizou-se autores que se debruçam sobre os conceitos analisados. Para o tema dos conflitos socioambientais compóem a pesquisa bibliográfica os autores: Acselrad (2004); Zhouri e Laschefski (2010); Little (2001); Santos (2015); Soares (2010); Carvalho (2005); Besen e Bellenzani (2013); Granja (2012); Barbanti (2003); Tundisi (2011); Caubet (2006). Já para o tema da educomunicação socioambiental utilizou-se estudos de autores como Peruzzo (2007); Soares (2009); Freire (2002); e Kaplún (1998) e da governança Jacobi e Sinisgalli (2012); Diniz (1999) e Soares (2008). Foi explorada a mediação como elemento presente nos conflitos hídricos, no campo do Direito fez-se uso dos estudos de Calmon (2008); Warat (2012) e Soares (2010) e no campo da Comunicaçáo Social de Bastos (2008); Júnior (2007), Figueiredo (sd) e Orozco (2001).

\section{REFERENCIAL TEÓRICO}

\subsection{Dimensóes de análise de conflitos socioambientais}

Autores que debruçam-se sobre a problemática dos conflitos socioambientais elencam dimensóes a serem consideradas em uma análise interpretativa: elementos materiais e os modos diferenciados de sua valoração; aspectos históricos e geográficos; posicionamentos políticos e redes de relaçóes; modos de viver e afetos que emergem da relação humana com o seu entorno e da percepçáo da necessidade de cuidado, diante da escassez decorrente do uso intensivo dos recursos naturais, das dinâmicas econômicas e dos modelos técnicos que caracterizam a relação entre sociedade e natureza.

Acselrad (2004) refere que os modos de apropriação do mundo material se articulam entre as formas técnicas e sociais, sendo que as técnicas são definidas a partir das diferentes estratégias de transformação do meio biofísico e as formas sociais expressam as diferenças entre as desigualdades de poder sobre os recursos ambientais e as formas culturais.

Assim, o conflito socioambiental é uma espécie particular de disputa que envolve diferentes representações de valor sobre o meio ambiente, as quais se dão a partir das práticas distintas de apropriação do mundo material, que podem ter natureza técnica, social ou cultural. Portanto, a configuração da base cognitiva para os discursos e açôes dos agentes 
envolvidos nos conflitos se dá de acordo com suas interpretaçóes e significados sobre a apropriação do território (ZHOURI; LASCHEFSKI, 2010).

O tipo de relação que os grupos sociais mantêm com o meio natural podem gerar disputas. Para Little (2001, p. 107) três bases compóem o conceito socioambiental: "[..] o mundo biofísico e seus múltiplos ciclos naturais, o mundo humano e as estruturas sociais e o relacionamento dinâmico e interdependente entre esses dois mundos”.

Portanto, uma contextualização social, histórica e geográfica se faz necessária para a análise do conflito ambiental, pois eles referem-se a questóes relativas a ambientes naturais particulares e atores sociais, cada um com características próprias. A contextualização de um conflito depende da escala básica em que ocorre, ou seja, se seu alcance é regional ou global, e da rede de relaçóes sociais e naturais que envolve. Do mesmo modo, Santos (2015) infere que as interaçóes, os contextos e as culturas são aspectos elementares a serem compreendidos a partir dos posicionamentos dos agentes envolvidos no conflito socioambiental.

A análise da conjuntura em que o conflito se desenvolve também é fundamental, pois historicamente ocorrem mudanças políticas, sociais e culturais (LITTLE, 2001) decorrentes de disputas ambientais, as quais explicitam situaçôes confusas e dinâmicas a serem analisadas, já que envolvem vários interesses em uma rede intrínseca de relaçóes (SOARES, 2010). Em síntese, dois fatores se presentificam na maioria dos conflitos ambientais: a crescente escassez dos recursos naturais, que, por outro lado, faz surgir a "[...] conscientização da necessidade de preservação e conservação ambiental” (CARVALHO, 2005, p. 28).

Dessa forma, as características dos recursos naturais, o que se produz ou quem produz em um dado espaço, ou ainda, quais são as ligaçóes afetivas e de identidade entre um grupo social e seu espaço, geram conflitos e contradiçôes sociais (BESEN; BELLENZANI, 2013). O conflito é inerente às relaçôes humanas em todas as sociedades, solicitando uma interpretação sobre modos de viver e resolver problemas considerados relevantes para as partes interessadas (GRANJA, 2012)

Os conflitos ambientais não são apenas conflitos que decorrem de movimentos sociais ou entre grupos sociais estanques. As dinâmicas sociais, políticas e econômicas das relaçóes que envolvem sociedade e natureza fazem emergir disputas sobre modos de valoração dos bens materiais e imateriais de um território, daí a necessidade de um enfoque interdisciplinar na sua abordagem. Uma única disciplina do conhecimento pode não ser suficiente para se analisar os conflitos relacionados à promoção de formas mais sustentáveis de desenvolvimento (BARBANTI, 2003). Acselrad (2004) concorda quando refere que os objetos constituintes do ambiente vão além da matéria e da energia, eles são também culturais e históricos.

Todos estes elementos e suas interrelaçóes conferem uma complexidade ao estudo sobre conflitos socioambientais, que devem ser contemplados tanto em intervençóes que emergem de políticas públicas quanto da sociedade civil organizada, na qual se inserem as iniciativas privadas que buscam o desenvolvimento com sustentabilidade. 


\subsection{Conflitos hídricos e educomunicaçáo socioambiental}

É preciso considerar que a água é um recurso natural fonte de diversas atividades de subsistência humana e essencial à vida, que se complexificam ao longo do processo histórico, especialmente com os usos exigidos pelos setores da indústria e da agricultura para fazer frente à necessidade de consumo consequência do aumento da população e da urbanização, que se intensificaram principalmente no século XX. Este cenário vai afetar disputas em torno da água, que passa a ser considerada um recurso, o que dá um viés de tratamento econômico a este elemento natural.

Um resumo dos principais problemas referentes à quantidade e à qualidade dos recursos hídricos no Brasil mostra uma situação diversificada e complexa, que exige avanços institucionais e tecnológicos para recuperação e proteção além de novas visóes para a gestão preditiva, integrada e adaptativa (TUNDISI, 2011, p. 136).

Por sua vez, Caubet (2006) sintetiza que em relação à água quatro elementos devem ser considerados: a importância extrema do recurso, a má distribuição, a escassez e a partilha. Esses quatro elementos conjugados produzem um contexto de disputa, mesmo que não seja declarado como tal. O autor cita o caso do rio Paraná entre Brasil e Argentina, quando da construção de Itaipu, como um conflito náo divulgado pela motivação em questóes relacionadas à água, mesmo considerando ter este fundamento.

Assim, este caráter da água ser elemento vital e escasso torna o seu uso disputado, gerando um contexto de conflito, que, como já referido expressam posicionamentos sobre modos de uso deste recurso, que envolvem aspectos culturais, relativos às várias visóes e linguagens, as quais, segundo Soares (2008), devem ser tratadas de forma inclusiva e dialógica compreendidas como uma oportunidade de crescimento pessoal e social.

Assim, para pensar o tratamento do conflito socioambiental hídrico e suas possibilidades de gerar processos de governança entende-se que as propostas do campo da educomunicação socioambiental podem trazer relevantes contribuições, especialmente porque valorizam as mediaçóes.

A educomunicação socioambiental é um campo novo de saber, reconhecido oficialmente como componente pedagógico dos processos comunicativos associados à educação ambiental no âmbito do Programa Nacional de Educação Ambiental (BRASILPNEA, 1999). As possibilidades de atuação da educomunicação socioambiental ultrapassa os contornos da educação formal e são realizadas a partir de uma perspectiva crítica da comunicação e da democracia (PERUZZO, 2007; SOARES, 2009).

As áreas que compóem este campo emergente de saber referem-se a uma construçáo epistemológica, à recepção crítica dos conteúdos midiáticos, à articulação de processos virtuais e presenciais formadores de "ecossistemas educativos", à democratizaçáo dos meios de comunicação colocando o receptor também como emissor, à capacitação para o uso dos meios e à percepção de que é inerente a dimensão educativa aos processos de comunicação (BRASIL, 2005).

Portanto, a educomunicaçáa socioambiental refere-se a relaçóes de comunicação que não necessariamente necessitam da mediação tecnológica. Mas sempre requerem o respeito 
aos princípios que a norteiam, os quais são: a) o diálogo permanente e continuado; b) a interatividade e produção participativa de conteúdos; c) a transversalidade; d) o encontro/ diálogo de saberes; e) a proteção e valorização do conhecimento tradicional e popular; f) a democratização da comunicação e a acessibilidade à informação socioambiental; g) o direito à comunicação; e h) a não discriminação e o respeito à individualidade e diversidade humana (BRASIL, 2008).

Kaplún (1998) destaca na educomunicação socioambiental a importância do processo de transformação das pessoas e das comunidades, preocupando-se com a interação dialética entre as pessoas e a realidade e com o desenvolvimento de suas capacidades intelectuais e da consciência social.

É o que Freire (2002) chama de educação como prática da liberdade, um processo em que todos participam de forma ativa e crítica, fundada na interaçáo dos sujeitos que exercem uma prática transformadora. É a busca do saber baseada nas trocas, no diálogo e nas relaçóes dos sujeitos com a realidade.

Trata-se de um campo que requer a mediação na construção de saberes e, portanto, contribui como método no enfrentamento de conflitos socioambientais, podendo desencadear processos de governança ambiental em relação à questão hídrica.

O conceito de governança refere-se ao conjunto de iniciativas, regras, instâncias e processos que permitem às pessoas, por meio de suas comunidades e organizaçóes civis, a exercer o controle social, público e transparente, das estruturas estatais e das políticas públicas, por um lado, e da dinâmica e das instituiçôes do mercado, por outro, visando a atingir objetivos comuns. [...] A Governança Ambiental está relacionada com a implementaçấo socialmente aceitável de políticas públicas, um termo mais inclusivo que governo, por abranger a relação Sociedade, Estado, mercados, direito, instituições, políticas e açóes governamentais, associadas à qualidade de vida bem-estar, notadamente os aspectos relacionados com a saúde ambiental. [...] A construção desse sistema é um processo participativo, e acima de tudo, de aprendizagem (JACOBI; SINISGALLI, 2012, p. 1.471)

Para Diniz (1999, p. 196) as novas condiçóes internacionais e a complexidade crescente da ordem social requerem um Estado mais flexível, descentralizado, que compartilha responsabilidades ampliando o universo dos atores participantes dos processos de decisão, sem abrir mão dos instrumentos de controle e supervisão.

Soares (2008) identificou que a maioria dos autores sobre o tema considera a melhor governança hídrica aquela realizada através da participação, envolvimento e negociação dos interessados, descentralização, integração, gestão por bacia hidrográfica e com mecanismos para resolução dos conflitos de forma pacífica, rápida e satisfatória.

Assim, coloca-se como hipótese que a governança possível de surgir a partir do tratamento de conflitos socioambientais, como os hídricos, decorre de processos de mediação, entendidos como uma dinâmica de troca multifacetada que assume diferentes nuances conforme os atores e cenários envolvidos nos conflitos socioambientais, e que tem em si duas dimensões fundamentais: da comunicação e pedagógica, sintetizadas na proposta do campo da educomunicação (suas áreas e princípios). 
Para o Direito, a mediação é o processo pelo qual um mediador facilita e/ou incentiva a autocomposição. Segundo Calmon (2008, p. 119) "mediação é a intervenção de um terceiro imparcial e neutro, sem qualquer poder de decisão, para ajudar os envolvidos em um conflito a alcançar voluntariamente uma solução mutuamente aceitável”. Warat (2012, p. 07) refere que o mediador cumpre a função de um terapeuta emocional e que a mediação "[...] es un trabajo de reconstrucción simbólica, imaginaria e sensible de producción de diferencias que permitan superar las divergências [...]”.

A mediação, procedimento no qual um terceiro imparcial facilita a comunicação, para que as próprias pessoas envolvidas solucionem seus conflitos, ressalta a cooperação, a igualdade de participação, a cidadania, construindo relaçóes e prevenindo futuras disputas (SOARES, 2008, resumo).

Portanto, na mediação o tratamento do conflito é alcançado por meio do diálogo, orientado pelo mediador, chegando-se ao consenso. Uma solução conjunta traz o fortalecimento das relaçóes de confiança e credibilidade, a prática de princípios como respeito, solidariedade e cooperação e o diálogo direto entre os envolvidos, evitando-se manipulaçóes autoritárias (SOARES, 2010).

Assim, permite a implementação da gestão ambiental de forma participativa e democrática e incentiva a lidar com o conflito como uma forma de aprendizagem e crescimento pessoal. A mediação pode viabilizar a política pública ambiental, ao mesmo tempo que permite uma transformação social, através da assunção de responsabilidade dos sujeitos frente ao meio em que vivem (SOARES, 2010).

Enquanto para o campo do Direito a mediação é compreendida como uma função de alguém, um terceiro neutro, em relação a um conflito, no âmbito da Comunicação Social, a mediação refere-se a uma composição complexa de relaçôes e ambientes, percebida como um "[...] pano de fundo onde as manifestaçôes comunicacionais orquestram tramas culturais. $\mathrm{O}$ conceito não tem contornos muito claros e compreende toda a gama de relaçóes e intersecçôes entre cultura, política e fenômeno comunicacional” (BASTOS, 2008, p. 86). Relaciona sujeitos, significações e mensagens em funçôes mais complexas do que a simples transmissão da informação por um emissor para um receptor. "Os espaços sociais, os espaços de relações sociais locais e suas situáveis de interação cotidianas (a casa, a vizinhança, o bairro, a escola etc.) estabelecem mediáveis na produçâo de sentido” (JÚNIOR, 2007, p. 09).

Assim, os sujeitos conflitantes sofrem constantemente a mediação de um complexo de relações e ambientes, o que interfere na comunicação entre eles. Ou seja, "as representaçóes, os textos, os discursos estariam diretamente relacionados a certos mapas e significados que permitiriam aos agentes sociais interpretar, conhecer, reconhecer, contestar e agir no mundo social" (JÚNIOR, 2007, p. 03). Orozco (2001) separa essas mediaçóes em micromediaçóes, que são aquelas advindas dos indivíduos particulares, com características próprias, produto de sua herança genética e de seu desenvolvimento e trajetória pessoal; e macromediaçóes, tem um caráter social, advindas da construção das identidades, de percepçóes advindas coletivamente e por meio das instituiçóes. 
Portanto, “[...] a mediação é uma espécie de estrutura incrustada nas práticas sociais cotidianas das pessoas, que, ao realizar-se através dessas práticas, se traduzem em múltiplas mediaçóes" (FIGUEIREDO, sd, p. 10).

Diante disso, percebe-se que este conceito de mediação da Comunicação Social pode contribuir na construção do conhecimento sobre a temática e na facilitação da comunicação entre os conflitantes. Ou seja, se as condutas estáo constantemente sofrendo mediaçóes de ambientes e relaçóes, o tratamento dos conflitos socioambientais deve levar em consideração essas interferências externas e internas na fala e no posicionamento das partes opostas, para, assim, superar as divergências e chegar a um consenso.

Portanto, na mediação em processos de educomunicação socioambiental e de governança ambiental são utilizadas metodologias que estimulam a participação, o diálogo e o engajamento para o tratamento do conflito socioambiental e a solução pelo consenso.

Galtung (2006) explica que se as partes tentarem ser menos hostis entre si, negociaçóes brandas e diretas podem surtir efeitos. Olhar para o passado, enfatizando o destrutivo ao invés do construtivo que está no futuro, é um problema que pode ser causado por fortes emoçóes, podendo paralisar toda a criatividade no trato dos conflitos. Estimular a criatividade por meio do diálogo, buscando que as partes encontrem uma imagem mais positiva umas das outras, faz com que nos apropriemos mais do conflito como também da solução. "Devemos nos desenvolver juntos a adquirir um senso de responsabilidade compartilhada” (GALTUNG, 2006, p. 180).

Em processos de mediação atrelados a conflitos socioambientais relacionados à questão hídrica múltiplas mediações interferem, decorrentes dos contextos social, político, econômico, geográfico, histórico, cultural, ético, etc., em que o problema está imerso. Esta multiplicidade de fatores é que compóem a dinâmica de troca multifacetada que se exige para o tratamento dos conflitos, e que assume diferentes nuances conforme os atores e cenários envolvidos neles. Muitas vezes, talvez na maior parte dos casos, o caráter dos conflitos solicita a interferência de atores mediadores, com características como aquelas que o campo do Direito sugere e embasa seu entendimento de mediação. Mas também requer que se contemplem aspectos comunicacionais e pedagógicos, sintetizadas na proposta educomunicativa.

\section{CONCLUSÃO}

A utilização de recursos naturais pela sociedade decorre de diferentes interesses. Dessa forma, as disputas ambientais estão permeadas por diversos fatores, como aspectos culturais, econômicos, sociais, históricos, políticos etc. Além disso, à água, um recurso vital e escasso, são dadas diferentes valoraçôes, decorrente de diferentes identidades e territórios a que está ligada. Para o melhor tratamento desse tipo de conflito complexo, se faz presente a participação e o diálogo para se alcançar processos de governança. A mediação e a educomunicação socioambiental são mecanismo para estimular o dialogismo e o engajamento na tomada da decisão e na execução das medidas alcançadas pelo consenso.

A educomunicação socioambiental é uma dimensão pedagógica dos processos comunicativos ambientais baseada no diálogo e na participação, bem como em engajamento 
e atravessamentos, com valorização do trabalho coletivo e do conhecimento tradicional ou popular.

Para a Comunicação Social, mediações relacionam sujeitos, significaçóes e mensagens em funçóes mais complexas que a simples transmissão da informação. Ou seja, cada ato possui um pano de fundo e é permeado por representaçóes e símbolos. Para o Direito, por sua vez, o mediador é um terceiro que facilita a comunicação entre as partes, estimulando o diálogo no tratamento de um conflito. Essas mediações tratam sobre a comunicação entre os sujeitos.

Portanto, para o alcance de processos de governança, em que se faz presente a integração e o compartilhamento de objetivos, as mediaçóes e a educomunicação socioambiental podem ser alternativas efetivas no tratamento de conflitos, pois utilizam-se de uma lógica baseada no diálogo e em uma perspectiva mais inclusiva.

Assim, a proposta do artigo foi refletir sobre as contribuições das metodologias participativas no tratamento dos conflitos hídricos por meio de revisão bibliográfica. Trata-se de uma etapa da tese de doutorado, que vai fazer um estudo de caso do Programa Cultivando Água Boa de Itaipu Binacional, situado na Bacia Hidrográfica do Paraná III, buscando investigar as contribuições da educomunicação socioambiental na construção de processos de governança ambiental. Dessa forma, se pretende contribuir com as reflexóes nesse campo.

\section{REFERÊNCIAS}

ACSELRAD, Henri. Conflitos ambientais no Brasil. Rio de Janeiro: Relume-Dumará, Fundação Heinrich Böll, 2004.

BARBANTI JÚNIOR, Olýmpio. Conflitos Socioambientais: teorias e práticas. 2003. Disponível em: <http://www.uni-tuebingen.de/egwinfo/susam/download/barbanti. pdf>.

BASTOS, Marco Toledo de Assis. Do sentido da mediaçáo: às margens do pensamento de Jesús Martín-Barbero. Revista FAMECOS, no 35. Porto Alegre, 2008.

BESEN, Gina R.; BELLENZANI, Maria L. Negociação e mediação de conflitos em Áreas de Preservação Ambiental - APAs. In: JACOBI, Pedro Roberto. Aprendizagem social e unidades de conservaçáo: aprender juntos para cuidar dos recursos naturais. $1^{\mathrm{a}} \mathrm{ed}$. IEE/ PROCAN: São Paulo, 2013.

BRASIL. Ministério do Meio Ambiente. Documentos técnicos. Programa de Educomunicação Socioambiental. 2005. Disponível em: <http://www.mma.gov.br/ estruturas/educamb/_arquivos/dt_02.pdf>. Acesso em: 01 jul. 2015.

BRASIL. Lei n. 9795, de 27 de abril de 1999. Política Nacional de Educação Ambiental. Disponível em: <http://www.planalto.gov.br/ccivil_03/leis/19795.htm>. Acesso em: 27 mar. 2015. 
BRASIL. Ministério do Meio Ambiente. Secretaria de Articulação Institucional e Cidadania Ambiental. Programa Nacional de Educação Ambiental. Educomunicação socioambiental: comunicação popular e educação. Organização: Francisco de Assis Morais da Costa. Brasília: MMA, 2008. Disponível em: <http://www.mma.gov.br/ estruturas/educamb/_arquivos/txbase_educom_20.pdf>. Acesso em: 10 abr. 2015.

CALMON, Petrônio. Fundamentos da mediaçáo e da conciliaçáo. Rio de Janeiro: Forense, 2008.

CARVALHO, Rocine C. Gestáo dos recursos hídricos: conflito e negociação na questão das águas transpostas da Bacia do Paraíba do Sul, RJ. 2005. 215 f. Tese de Doutorado (Ciências em Planejamento Energético) - Universidade Federal do Rio de Janeiro, Rio de Janeiro, março 2005.

CAUBET, Christian G. A água doce nas relaçóes internacionais. Barueri: Manole, 2006.

DINIZ, Eli. Crise, reforma do Estado e governabilidade. Brasil, 1985-1995. Rio de Janeiro: Fundação Getúlio Vargas, 1999. 228 p.

FIGUEIREDO, Ana Maria Camargo. Uma leitura crítica: a proposta teórica integracionista latino-americana de Jesús Martín Barbero. sd. Disponível em: <http:// www.portcom.intercom.org.br/pdfs/129786361888326032325193641839043378162. pdf.> Trabalho apresentado no NP Teorias da comunicação.

FREIRE, Paulo. Extensão ou Comunicação? São Paulo: Paz e Terra, 2002.

GALTUNG, Johan. Transcender e transformar: uma introdução ao trabalho de conflitos. São Paulo: Palas Athena, 2006.

GRANJA, Sandra Inês Baraglio. Manual de Mediação de Conflitos Socioambientais. In: BESEN, Gina Rizpah (Org). 5 Elementos Instituto de Educação e Pesquisa Ambiental. UMAPAZ - Universidade Aberta do Meio Ambiente e da Cultura de Paz, 2012.

JACOBI, Pedro Roberto; SINISGALLI, Paulo Antonio de Almeida. Governança ambiental e economia verde. Ciência \& Saúde Coletiva, 17(6):1469-1478, 2012.

JÚNIOR, Girardi Ilráucio. Teoria das mediaçóes e estudos culturais: convergências e perspectivas. Intercom - Sociedade Brasileira de Estudos Interdisciplinares da Comunicação XXX Congresso Brasileiro de Ciências da Comunicação - Santos - 29 de agosto a 2 de setembro de 2007.

KAPLÚN, Mario. Una Pedagogia de la Comunicación. Madrid: Ediciones de la Torre, 1998. 
LEFF, Enrique. Racionalidade ambiental: a reapropriação social da natureza. Rio de Janeiro: Civilização Brasiliera, 2006.

LITTLE, Paul Elliot. Os conflitos socioambientais: um campo de estudo e de ação política. In: BURSZTYN, Marcel (Org.). A difícil sustentabilidade: política energética e conflitos ambientais. Rio de Janeiro: Garamond, 2001. P. 107-122.

OROZCO, Guilhermo. Televisión, audiencias y educacion. Buenos Aires: Grupo Editorial Norma, 2001.

PERUZZO, Cecília M. Kroling. Radio comunitária, educomunicação e desenvolvimento local. In: PAIVA, Raquel. O retorno da comunidade: os novos caminhos do social. Rio de Janeiro: Editora Mauad, 2007.

SANTOS, Bianca Borges Medeiros Santos. Comitês de Bacia Hidrográfica como Instrumento de Resolução de Conflitos sobre a Água: uma Análise sobre o Comitê Guandu (RJ) e a CTR Santa Rosa (RJ). In: Anais do 70 Encontro Nacional da ANPPAS, 2015.

SOARES, Samira Iasbeck de Oliveira. Mediação de conflitos ambientais: um novo caminho para a governança da água no Brasil? Curitiba: Juruá, 2010.

. A mediação de conflitos na gestáo de recursos hídricos no Brasil. 2008. 172 p. Dissertação (mestrado) - Programa de Ciência Ambiental, Universidade de São Paulo, São Paulo, 2008.

SOARES, Ismair de Oliveira. Caminos de La educomunicación: utopias, confrontaciones, reconocimientos. Nómodas, Universidad Central, Bogotá, Colombia, n. 30, p. 194-207, Abril de 2009.

SIMMEL, Georg. O conflito da cultura moderna e outros escritos. São Paulo: Senac, 2013.

TUNDISI, Takako Matsumura. Recursos hídricos no século XXI. São Paulo: Oficina de Textos, 2011.

WARAT, Luis Alberto. Mediación, el derecho fuera de las normas: para una teoría normativa del conflicto. Scientia Iuris, v. 4, 2012.

ZHOURI, Andréa; LASCHEFSKI, Klemens. Desenvolvimento e conflitos ambientais: um novo campo de investigação. In: ZHOURI, A.; LASCHEFSKI, K. (Orgs.).

Desenvolvimento e conflitos ambientais. Belo Horizonte: Editora UFMG, 2010, p. 11-31. 